\title{
Prolonged incubation in seawater induces a DNA-dependent protein phosphorylation activity in Arbacia punctulata eggs
}

\author{
Jyotshnabala Kanungo* \\ Laboratory of Molecular and Developmental Biology, National Eye Institute, National Institutes of Health, Bethesda, MD 20892, USA \\ Received 14 May 2002
}

\begin{abstract}
Various protein kinases are activated in eggs in response to fertilization. We have previously shown that the induction of DNAdependent protein phosphorylation activity in the sea urchin eggs is triggered by fertilization. The present study demonstrates that the activation of a DNA-dependent serine/threonine kinase in unfertilized eggs of Arbacia punctulata can be achieved without fertilization. Prolonged incubation in seawater resulted in the activation of the eggs with concomitant induction of DNA-dependent protein phosphorylation activity. The activated eggs when fertilized show a slight increase in the phosphorylation activity 10-min post-insemination. The activity gradually declines as the first and second cleavages proceed. The cytoplasmic extracts of the blastulae, gastrulae, and plutei lack the enzyme activity. These findings reveal that not only fertilization but also egg activation serves as a signal for the induction of a DNA-dependent protein phosphorylation activity in sea urchin eggs suggesting that spermentry is not required for the induction of the enzyme activity. Published by Elsevier Science (USA).
\end{abstract}

Keywords: Egg activation; DNA-inducible kinase; Early development

DNA-dependent protein phosphorylation has been reported in various organisms including sea urchins [1-6]. In mammalian cells, the DNA-dependent protein kinase (DNA-PK) responsible for this activity is a serine/threonine kinase that requires double-stranded (ds) DNA for its activity [7]. The enzyme plays a crucial role in DNA repair [8] apart from being a player in different other cellular events such as apoptosis [9]. However, its participation in embryonic development has not been extensively investigated. In our previous reports [3,4], we demonstrated that fertilization acts as a signal for the appearance of a DNA-inducible kinase activity which disappears gradually from the cytoplasmic extracts prepared from the embryos as development proceeds. Immunocytochemical evidences further supported this observation by demonstrating the nuclear translocation of a protein, immunologically identical to the catalytic subunit (p460) of DNA-PK in the later embryos. All these observations were strengthened by the use of a specific peptide substrate and monoclonal antibodies

\footnotetext{
${ }^{*}$ Fax: +1-301-435-7678.

E-mail address: kanungoj@nei.nih.gov.
}

against the human enzyme that identified a similar polypeptide in immunoblot analysis of sea urchin egg extracts. Based on the crucial observation that the cytoplasmic extracts of unfertilized eggs did not have DNA-inducible kinase activity and fertilization resulted in the induction of the enzyme activity, it was relevant to explore whether stimuli other than fertilization could also induce the enzyme activity. This study shows that prolonged incubation of the unfertilized eggs in seawater that results in the nuclear envelope breakdown can induce the enzyme activity. The results indicate that the physiological change(s) associated with the egg activation is equally a potent signal as fertilization to induce the activation of a DNA-dependent protein phosphorylation activity.

\section{Materials and methods}

Unless and otherwise indicated all chemicals were purchased from Sigma. All the experiments were performed at the Marine Biological Laboratory (Woods Hole, Massachusetts).

Collection of eggs and embryos: Male and female Arbacia punctulata were obtained and the gametes were shed in artificial seawater for egg activation and fertilization. Eggs incubated in artificial seawater did 
not undergo activation at least up to $7 \mathrm{~h}$ at $15^{\circ} \mathrm{C}$. Eggs incubated in natural seawater, henceforth referred to as 'seawater,' for $5 \mathrm{~h}$ at $15^{\circ} \mathrm{C}$ underwent $85-90 \%$ nuclear envelope breakdown. Observing a small batch of eggs every $30 \mathrm{~min}$ under a microscope monitored scoring of the nuclear envelope breakdown. Embryos at different stages were collected following fertilization of these activated eggs at various time intervals.

Extract preparation: Eggs and embryos were harvested by hand centrifugation. Cytoplasmic extract was prepared following the procedure of Ballinger et al. [10]. Briefly, the eggs and embryos were homogenized in a Dounce homogenizer in $50 \mathrm{mM}$ HEPES, pH 7.4, $10 \mathrm{mM}$ EGTA, $40 \mathrm{mM} \mathrm{NaCl}, 100 \mathrm{mM}$ potassium acetate, $8.56 \mathrm{mM}$ $\mathrm{CaCl}_{2}, 2.29 \mathrm{mM} \mathrm{MgCl}$, and $277 \mathrm{mM}$ glycerol. Centrifugation of the homogenate was performed $\left(12,000 \mathrm{~g} \times 30 \mathrm{~min}, 4^{\circ} \mathrm{C}\right)$ to separate particulate components from soluble components.

DNA-dependent protein kinase assay: DNA-inducible kinase activity was performed as reported earlier using the cytoplasmic extracts as a source of the enzyme [2,3]. Dephosphorylated $\alpha$-casein and a specific peptide derived from p53 (EPPLSQEAFADLWKK) [8] were used as substrates. A mutant peptide (EPPLSEQAFADLWKK) was used in the enzymatic assays as a non-specific substrate. To analyze casein phosphorylation, the phosphorylation reaction products were resolved on 10\% SDS-polyacrylamide gels followed by autoradiography. The peptide phosphorylation was analyzed by spotting the reaction products on p81 phosphocellulose disks and counting in a scintillation counter after several washes with $30 \%, 15 \%$ acetic acid and acetone, respectively. The incorporation of ${ }^{32} \mathrm{P}$ to the peptide substrate was calculated after subtracting the value obtained from the mutant, nonspecific peptide.

\section{Results and discussion}

Previously we have shown that a DNA-inducible protein kinase activity in unfertilized eggs of Arbacia is undetectable. However, the activity is induced upon fertilization [3]. Possibilities remained that stimuli other than fertilization could also induce the enzyme activity. To explore this possibility, first, optimization of the kinase reaction condition especially the reaction time was undertaken. Fig. 1 shows that homogenate-catalyzed DNA-dependent protein phosphorylation activity is optimal at $30 \mathrm{~min}$. $\alpha$-Casein (Fig. 1A) and the specific peptide (Fig. 1B) were maximally phosphorylated after $30 \mathrm{~min}$ although the activity was insignificantly different from 15-, 45-, and 60-min reaction time points. Thus, for all the experiments, kinase activity assays were performed on the basis of a 30-min reaction time. To demonstrate the activation of a DNA-inducible protein kinase by various forms of nucleic acids, homogenatecatalyzed enzyme assay was performed in eggs and embryos of Arbacia. Effect of the addition of different types of nucleic acids and an oligonucleotide on the activation of the enzyme to phosphorylate exogenously added $\alpha$-casein (Fig. 2A) and specific peptide (Fig. 2B) in the extract was examined. Activation of a kinase activity by sonicated double-stranded DNA was observed in the cytoplasmic extracts prepared from eggs $10^{\prime}$ postfertilization (Fig. 2). In contrast, addition of equal amounts (75 ng) of total RNA and single-stranded DNA that was prepared by boiling the dsDNA for $5 \mathrm{~min}$
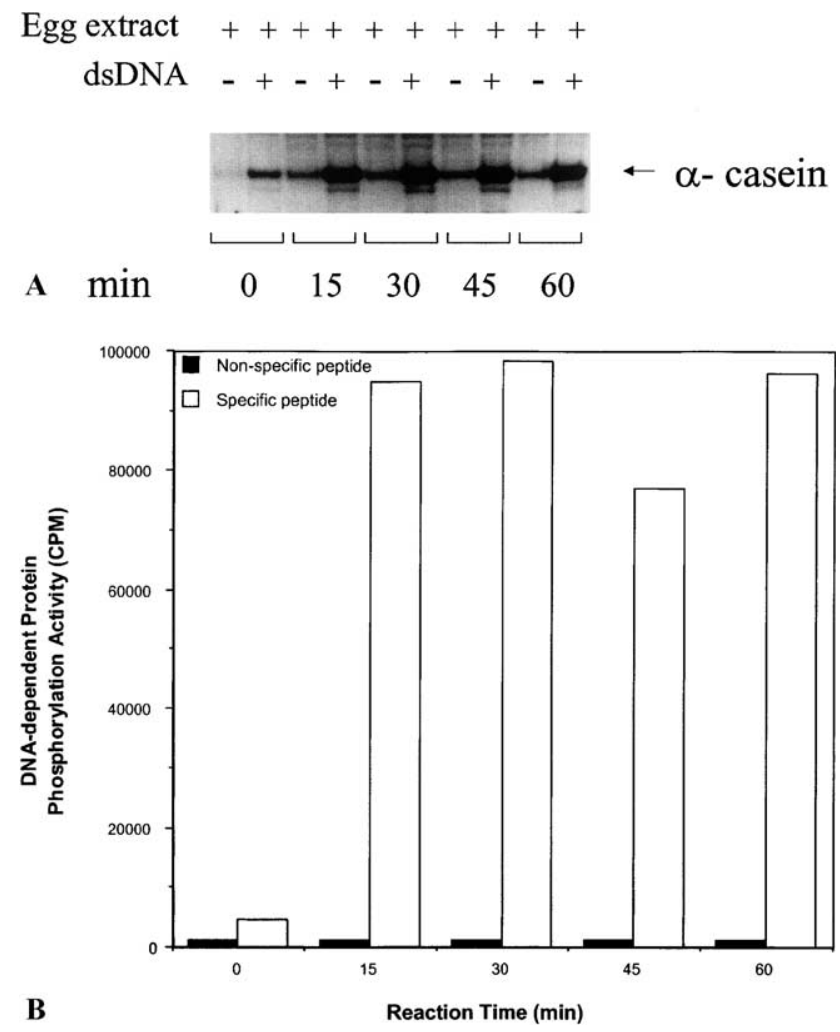

Fig. 1. Optimization of reaction time for DNA-dependent protein phosphorylation activity assay. Cytoplasmic extract was prepared from fertilized eggs 10-min post-insemination. DNA-dependent protein phosphorylation assay was performed using $\alpha$-casein and a specific peptide as substrates. Adding $75 \mathrm{ng}$ sonicated, double-stranded calf thymus DNA induced the enzyme activity. The kinase reactions were terminated at various time intervals between 0 and $60 \mathrm{~min}$. (A) Reaction products where $\alpha$-casein was used as a substrate were analyzed on a 10\% SDS-polyacrylamide gel and autoradiographed. (B) Reaction products where a specific peptide was used were spotted onto phosphocellulose disks and counted for ${ }^{32} \mathrm{P}$-incorporation.

followed by quick cooling in ice, did not induce the enzyme activity as determined by phosphorylation of the exogenous substrates. A 25-mer single-stranded oligonucleotide was equally inefficient in activating the enzyme.

The presence of a polypeptide immunologically identical to the catalytic subunit of the human DNAdependent (DNA-inducible) kinase in sea urchin eggs and the induction of the enzyme activity $10 \mathrm{~min}$ postfertilization $[3,4]$ led to the assumption that the nuclear envelope breakdown may be the cause of the activation of the enzyme. Extracts prepared from the eggs which were incubated for $5 \mathrm{~h}$ in seawater instead of artificial seawater underwent nuclear envelope breakdown and showed a DNA-inducible protein phosphorylation activity (Fig. 3). Under such conditions, approximately $85-90 \%$ of the eggs underwent nuclear envelope breakdown. Therefore, the extracts cannot be termed exclusively cytoplasmic since there is no definitive 

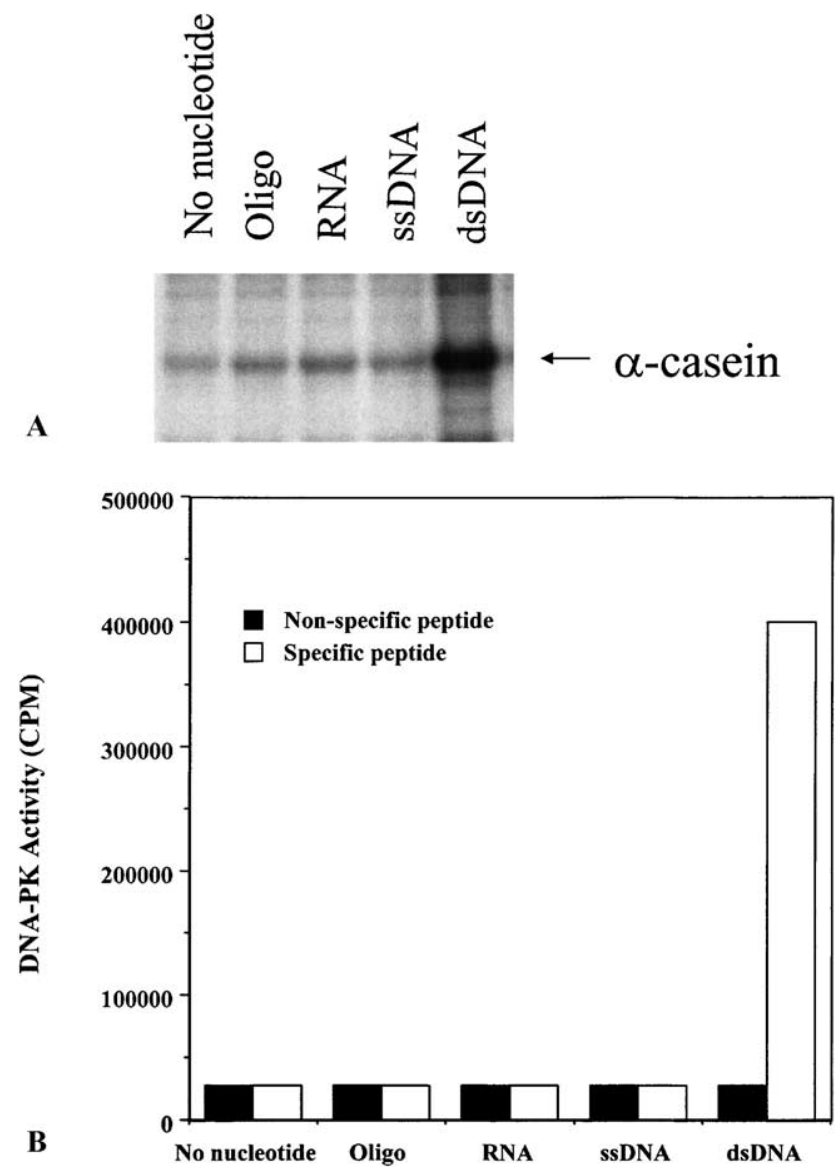

Fig. 2. Double-stranded DNA but not RNA, single-stranded DNA or oligonucleotide induces a protein kinase activity in Arbacia egg extracts prepared 10-min post-fertilization. A $15-\mu 1$ reaction required $10 \mu \mathrm{l}$ crude egg extract (approximately equivalent to $12 \mathrm{eggs}$ ), $15 \mu \mathrm{g}$ dephosphorylated $\alpha$-casein (A) or the specific peptide (B) as substrates, $2 \mathrm{mM} \mathrm{MgCl}$, and $130 \mu \mathrm{M}$ ATP. The reaction was carried out at $15^{\circ} \mathrm{C}$ and started by adding $10 \mu \mathrm{Ci}$ of $\left[{ }^{32} \mathrm{P}\right] \mathrm{ATP}(6000 \mathrm{Ci} / \mathrm{mmol})(\mathrm{NEN}, \mathrm{Du}$ Pont). The phosphorylation reaction product $(1 \mu \mathrm{l})$ was analyzed on a $10 \%$ polyacrylamide gel. The activity was induced in crude extracts by adding $75 \mathrm{ng}$ sonicated double-stranded DNA (dsDNA), total RNA, and single-stranded DNA (ssDNA) from calf thymus as well as a 23-mer single-stranded oligonucleotide. Dephosphorylated $\alpha$-casein was used as the exogenous substrate (arrow).

nucleus in these activated eggs. Interestingly, mechanical breakdown of the nucleus by sonication, in contrast, does not activate the DNA-inducible kinase activity [4]. It is assumed that the physiological egg activation process that is accompanied by several biochemical changes including activation of several protein kinases [11-15] is responsible for the activation of DNA-inducible phosphorylation activity.

To demonstrate whether the fertilization and prolonged incubation in seawater followed a similar pattern of the induction of a DNA-dependent protein phosphorylation activity, eggs incubated in seawater for $5 \mathrm{~h}$ were fertilized by artificial insemination. There was a slight increase in the enzyme activity as measured 10-min post-fertilization (Fig. 3). The eggs incubated in artificial seawater for $5 \mathrm{~h}$ did not show the DNA-inducible $\alpha$-casein phosphorylation (Fig. 3A). In the extracts prepared from the eggs incubated in seawater for $5 \mathrm{~h}$, $\alpha$-casein (Fig. 3A) and the specific peptide (Fig. 3B) were phosphorylated even without fertilization. In this batch of eggs, $\alpha$-casein phosphorylation increased 1.2-fold in fertilized eggs compared to that in the pre-fertilized eggs. The apparent slight increase in the enzyme activity could be attributed to the breakdown of nuclear envelopes of the eggs $(10-15 \%)$ that did not respond to seawaterinduced activation but were activated upon fertilization. At this point, it is conceivable that physiological processes associated with egg activation rather than spermentry are sufficient to induce the DNA-dependent protein phosphorylation activity. In Fig. 3A, $\alpha$-casein was phosphorylated after $10^{\prime}$ of fertilization even in the absence of dsDNA in the reaction. The trend continued through 50- and 103-min post-fertilization. However, there was no such dsDNA-independent $\alpha$-casein phosphorylation visible blastula stage onward. The results indicate that some other protein kinase(s) was activated as well 10-min post-fertilization. This assumption is consistent with the specific peptide phosphorylation assay (Fig. 3B) where the other activated kinase(s) could not phosphorylate the specific substrate. With further developmental progress, there was a gradual loss of cytoplasmic enzyme activity that was observed after $50^{\prime}$ and $103^{\prime}$ post-insemination when the first and second cleavages occurred. The activity was barely detectable blastula stage onward. This pattern of change in the enzyme activity is consistent with the results reported earlier in embryos obtained by fertilizing the non-activated eggs [3] which could be due to the nuclear translocation of the enzyme during later development [4].

In an earlier report, we demonstrated that microinjection of an antibody against the regulatory subunit of the human DNA-dependent protein kinase (DNA-PK) arrested cell division of the sea urchin eggs [6]. The results suggested a potentially important role of the DNA-dependent protein kinase during sea urchin development. The role of DNA-PK in DNA repair and apoptosis has been emphasized in mammals $[8,9]$. During a longer incubation in seawater the passive unfertilized eggs could undergo apoptosis and therefore an endogenously protective operation by activating the DNA-inducible protein kinase could in part act as a survival signal. Here, this study identifies that prolonged incubation in seawater can be a stimulus to induce DNA-inducible kinase activity that might be present in a cryptic form in the non-activated eggs. The mechanism of activation of the enzyme is, at present, not known. Additionally, several other agents that result in the nuclear envelope breakdown, for e.g., calcium ionophores need to be tested in terms of consequential 
artificial sea

water

sea water incubation

incubation
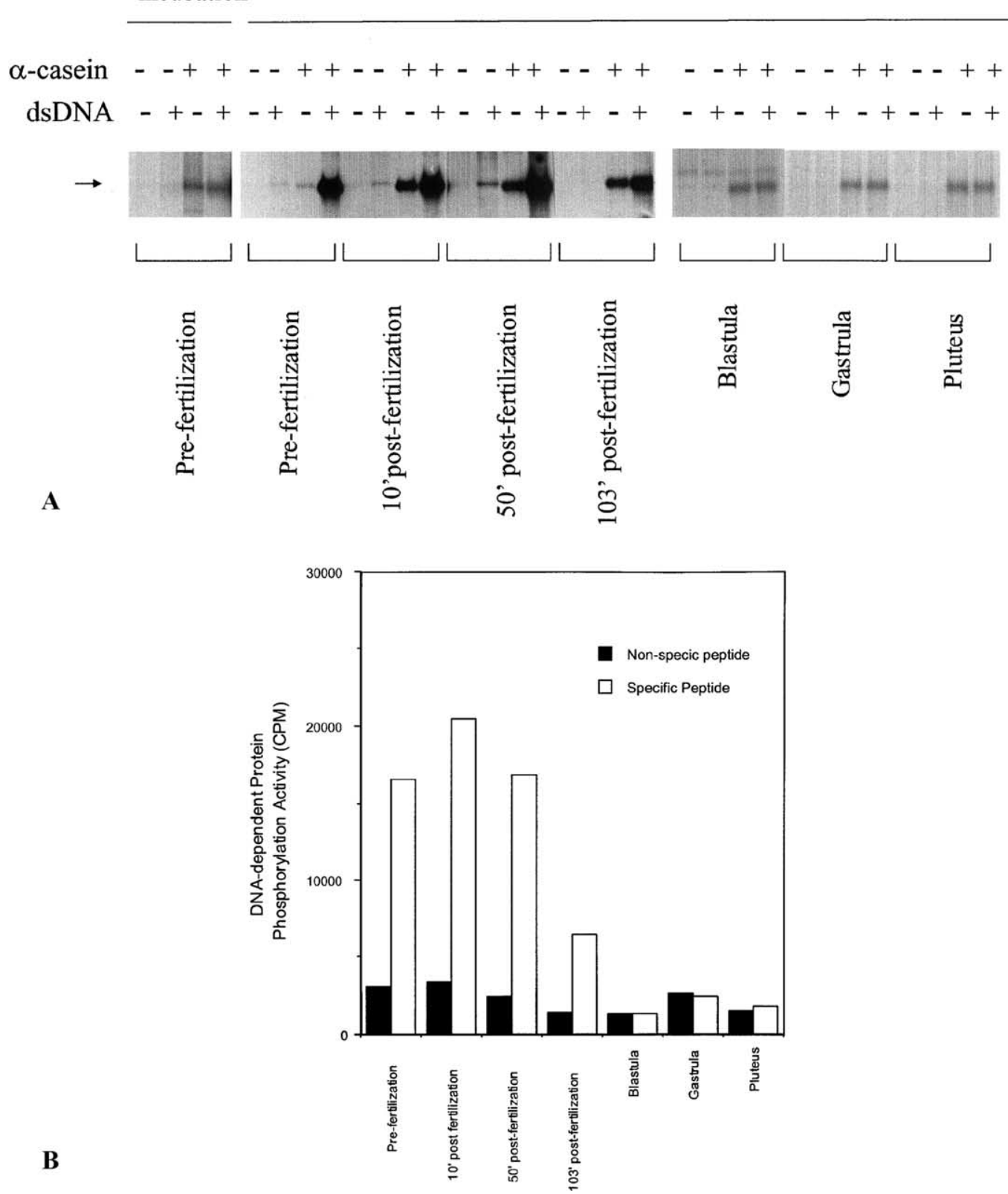

Fig. 3. (A) Autoradiogram shows variation in DNA-inducible protein phosphorylation activity during embryonic development. Cytoplasmic extracts from eggs and embryos were prepared. A $15-\mu$ reaction required $10 \mu$ cytoplasmic extract (approximately equivalent to 12 eggs or embryos), $75 \mathrm{ng}$ sonicated calf thymus DNA, $15 \mu \mathrm{g}$ dephosphorylated $\alpha$-casein as substrate, $2 \mathrm{mM} \mathrm{MgCl}_{2}$, and $130 \mu \mathrm{M}$ ATP. The reaction was carried out at $15^{\circ} \mathrm{C}$ and started by adding $10 \mu \mathrm{Ci}$ of $\left.{ }^{32} \mathrm{P}\right] \mathrm{ATP}(6000 \mathrm{Ci} / \mathrm{mmol})(\mathrm{NEN}$, Du Pont). The phosphorylation reaction $(1 \mu \mathrm{l})$ was analyzed on a $10 \%$ polyacrylamide gel. Arrow indicates the position of phosphorylated $\alpha$-casein. Absence and presence of dsDNA in the extract are indicated by - and + , respectively. (B) DNA-dependent protein kinase activity of cytoplasmic extracts prepared from eggs and embryos of Arbacia. Kinase reactions were set up exactly as described above except that a specific peptide derived from p53 was used as a substrate for parallel reactions. Reaction products were spotted unto p81 phosphocellulose paper disks, which were washed successively with $30 \%$ acetic acid, $15 \%$ acetic acid (three times), and then acetone. Scintillation counting quantitated the ${ }^{32} \mathrm{P}$ incorporated on the dried filters.

DNA-inducible kinase activation. Post-translational modification of the enzyme subunits following egg activation that could modulate the enzyme activity is another possibility that needs to be investigated. Whether specific inhibition of the DNA-inducible protein kinase activity would prevent egg activation and therefore further development of Arbacia would be of interest to the developmental biologists. 


\section{Acknowledgments}

I am grateful to Dr. Howard Rasmussen (Institute of Molecular Medicine and Genetics, Medical College of Georgia, Augusta) for laboratory facility, ideas, encouragement, and all the support for this work. I am thankful to Drs. Carl Anderson, William Dynan, John A. Hardin, Richard Cameron, and Roni Bollag for crucial discussions.

\section{References}

[1] A.I. Walker, T. Hunt, R.J. Jackson, C.W. Anderson, Doublestranded DNA induces the phosphorylation of several proteins including the 90,000 mol. wt. heat-shock protein in animal cell extracts, EMBO J. 4 (1985) 139-145.

[2] N.J. Finnie, T.M. Gottlieb, T. Blunt, P.A. Jeggo, S.P. Jackson, DNA-dependent protein kinase activity is absent in xrs-6 cells: Implications for site-specific recombination and DNA doublestrand break repair, Proc. Natl. Acad. Sci. USA 92 (1995) 320-324.

[3] J. Kanungo, B. Calhoun, Y. Takeda, J.A. Hardin, H. Rasmussen, Gradual loss of a DNA-inducible protein kinase activity from the cytoplasmic extracts of Arbacia embryos, Biol. Bull. 191 (1996a) 281-282.

[4] J. Kanungo, J.A. Walker, D. Woodrum, J.A. Hardin, H. Rasmussen, A DNA-inducible kinase activity undergoes a change in cellular localization during development in Arbacia, Biol. Bull. 191 (1996) 283-284.

[5] J. Kanungo, R.S. Cameron, Y. Takeda, J.A. Hardin, DNA-dependent protein phosphorylation activity in Xenopus is coupled to a Ku-like protein, Biol. Bull. 193 (1997) $147-152$.

[6] J. Kanungo, R.M. Empson, H. Rasmussen, Microinjection of an antibody to the $\mathrm{Ku}$ protein arrests development in sea urchin embryos, Biol. Bull. 197 (1999) 341-347.

[7] T. Carter, I. Vancurova, I. Sun, W. Lou, S. DeLeon, A DNAactivated protein kinase from HeLa cell nuclei, Mol. Cell. Biol. 10 (1990) 6460-6471.

[8] C.W. Anderson, DNA damage and the DNA-activated protein kinase, Trends Biochem. Sci. 18 (1993) 433-437.

[9] K. McConnell, W.S. Dynan, The DNA-dependent protein kinase: a matter of life and (cell) death, Curr. Opin. Cell Biol. 8 (1996) 325-330.

[10] D.G. Ballinger, S.J. Bray, T. Hunt, Studies of the kinetics and ionic requirements for the phosphorylation of ribosomal protein S6 after fertilization of Arbacia punctulata eggs, Dev. Biol. 101 (1984) 192-200.

[11] N. Satoh, D.L. Garbers, Protein tyrosine kinase activity of eggs of the sea urchin $S$. purpuratus: The regulation of its increase after fertilization, Dev. Biol. 111 (1985) 515-519.

[12] G. Peucellier, P.A. Veno, W.H. Kinsey, Protein tyrosine phosphorylation in response to fertilization, J. Biol. Chem. 263 (1988) 13806-13811.

[13] B. Ciapa, D. Epel, A rapid change in phosphorylation on tyrosine accompanies fertilization of sea urchin eggs, FEBS Lett. 295 (1991) 167-170.

[14] Y.A. Abassi, K.R. Foltz, Tyrosine phosphorylation of sperm receptor at fertilization, Dev. Biol. 164 (1994) 430-443.

[15] W.H. Kinsey, Biphasic activation of Fyn kinase upon fertilization of the sea urchin egg, Dev. Biol. 174 (1996) 281-287. 